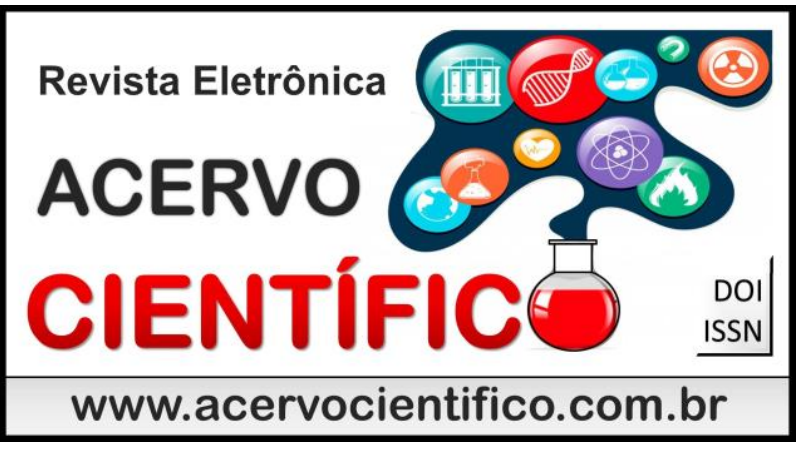

DOI: 10.25248/REAC.e329.2019

Recebido em: 8/2018

Aceito em: $9 / 2018$

Publicado em: 10/2018

\title{
Uma abordagem das práticas de letramento, escrita, leitura e oralidade numa perspectiva educacional
}

An approach literacy practices, writing, reading and speaking in an educational perspective

Un enfoque de las prácticas de letras, escrita, lectura y oralidad en una perspectiva educacional

Isonete do Socorro Sardinha Perna ${ }^{1}$ Rosenildo da Costa Pereira*

\begin{abstract}
Resumo: $O$ presente trabalho tem por finalidade expor uma reflexão das práticas de letramento, escrita, leitura e oralidade, destacando os aspectos de conhecimento de mundo numa perspectiva educacional. Como pressuposto teórico metodológico partiu-se de uma abordagem de estudos teóricos sobre a temática pesquisada. O estudo bibliográfico aponta que os aspectos da oralidade, escrita, leitura e letramento são fundamentais para o aprendizado dos educandos no contexto do espaço escolar formal.
\end{abstract}

Palavras-chave: Letramento; Escrita; Leitura; Oralidade.

Abstract: The present work aims to expose a reflection of the practices of literacy, writing, reading and orality, highlighting the aspects of world knowledge in an educational perspective. As a theoretical and methodological assumption, it was based on an approach of theoretical studies on the research topic. The bibliographic study points out that the aspects of orality, writing, reading and literacy are fundamental for the students' learning in the context of the formal school space.

Keywords: Letramento; Writing; Reading; Orality.

Resumen: El presente trabajo tiene por finalidad exponer una reflexión de las prácticas de letra, escritura, lectura y oralidad, destacando los aspectos de conocimiento del mundo desde una perspectiva educativa. Como supuesto teórico metodológico se partió de un abordaje de estudios teóricos sobre la temática investigada. El estudio bibliográfico apunta que los aspectos de la oralidad, escritura, lectura y letramento son fundamentales para el aprendizaje de los educandos en el contexto del espacio escolar formal.

Palabras clave: Letramento; escrito; lectura; Oralidad.

\footnotetext{
${ }^{1}$ Especialista em Estudo de Língua e Literatura Vernácula e em Educação do Campo pela Universidade Federal do Pará (UFPA). Professora da Secretaria Municipal de Educação de Abaetetuba.

2 Doutorando em Antropologia pela Universidade Federal do Pará (UFPA). Servidor Público da Secretaria de Educação do município de Abaetetuba. *E-mail: rosenildocosta@bol.com.br
} 


\section{INTRODUÇÃO}

Considerando que aquisição do desenvolvimento de letramento, escrita, leitura e oralidade levam-nos a pensar no ato de interação, na troca de experiências, no prazer da comunicação, nas maravilhas que essas práticas de conhecimento podem proporcionar ao educando.

Letramento, escrita, leitura e oralidade são modalidades de uso da língua adquirida pelos grupos sociais no processo de interação. São formas de apropriação e comunicação da língua.

Compreendê-los como aspectos que envolvem o processo de aquisição da estrutura da língua, desde o início da fala até a sua forma mais complexa de uso pela população, implicando no reconhecimento de que o aprendizado destes mecanismos da língua se dá de forma diferenciada entre os sujeitos sociais.

Neste sentido, esse trabalho pretende abordar com base nas teorias dos autores, Stubbs (2002), Bourdieu (2010), Sousa (2010), Bortoni-Ricardo (2005), Rodrigues (2007) e Marcuschi (2001) uma reflexão a respeito das práticas de letramento, escrita, leitura e oralidade numa perspectiva educacional, uma vez que essas práticas ainda estão deixando a desejar no ambiente escolar, sabendo que, se houver um bom desenvolvimento fará com que o sujeito torne-se ativo em sua aprendizagem.

O objetivo deste texto é discutir as práticas de letramento, leitura, escrita e oralidade com foco em uma perspectiva educacional, cujo propósito é mostrar a importância destas modalidades da língua para o aprendizado dos educandos em contexto escolar.

\section{LETRAMENTO, ESCRITA, LEITURA E ORALIDADE: UMA PERSPECTIVA EDUCACIONAL}

As práticas de letramento são usos culturais, ou seja, é um conhecimento que vai além da leitura significativa que o sujeito faz a partir de seu conhecimento de mundo. Entende-se, a partir de Marcuschi (2001), que os eventos e práticas de letramento acontecem em diferentes contextos sociais.

Dentre os mais variados contextos sociais básicos da vida cotidiana em que escrita e oralidade ocorrem como eventos e práticas de letramento, Marcuschi aborda, entre outros: o trabalho, a escola, o dia-a-dia, a família, a vida burocrática, a atividade intelectual, considerando que esses eventos acontecem através de gêneros discursivos e textuais variados.

Com relação ao letramento, Bourdieu (2010) adotou uma perspectiva de classe. Ele analisou que o insucesso do aluno se dá na assimetria, nas questões de ordem linguísticas (aluno/ professor/Escola/país), que se beneficia na perspectiva de classe, é a classe dominante que joga no aprendiz o complexo da incompetência linguística, a fim de aquela classe manter seu status.

Ou seja, nessa perspectiva, a escola passa a impor, através das práticas de leituras escolares, formas de apropriação e produção textual considerada legítima dos textos escritos. Segundo Bourdieu (2010), a leitura do texto escrito passou a exigir uma atitude de compreender por compreender e não de compreender para agir; a exigir o reconhecimento do status social de que é revestido o texto escrito, que direciona seu uso, manipula sua recepção, condicionam a sua leitura. Exigindo uma relação com a linguagem que ela tem por função ensinar, a escola passou a excluir aqueles que não tiveram acesso à mesma herança cultural.

Stubbs (2002) ressalta que a escola e o aluno tem papel igualmente de reconhecimento um da cultura do outro, ou seja, o aluno deve respeito à realidade da escola do mesmo modo que a escola também deve respeitar a cultura do aluno, não hierarquizando um em relação ao outro quanto ao uso da língua falada.

De acordo com a concepção do autor, as escolas assim como o aluno precisam estar preparados para que ambos possam atender suas necessidades, sabendo que, esse espaço irá dispor de uma diversidade linguística e sócio cultural.

Mas podemos perceber que muitas vezes há falhas por parte desse ambiente escolar que deixa de realizar um ensino aprendizagem de qualidade, pois segundo Stubbs (2012) o processo do uso da leitura é ensinado nas escolas após os anos iniciais do ensino, acarretando assim um ensino deficiente quanto à interpretação e compreensão da mesma. Dessa forma, a escola não estará formando um sujeito leitor. 
Sousa (2010) afirma que a leitura é de fundamental importância no aprendizado do aluno. Porém, as escolas ainda não estão preparando-os como deveriam, acarretando assim uma maior dificuldade na aprendizagem de aquisição da leitura por parte dos educandos.

Além disso, Sousa (2010) ressalta que, a leitura é vista como uma necessidade da sociedade vigente e que é preciso despertar pelo aluno e no aluno o prazer por ela. Numa perspectiva de que os educandos se envolvam com a prática da leitura, tornando-se não como uma atividade obrigatória, mas como uma forma prática social que possibilita interagir no mundo por meio das descobertas possibilitadas pela prática da leitura.

Contudo, para que a leitura possa torna-se um fator essencial é necessário que haja um interesse de ambas as partes e que a interpretação-compreensão possa acontecer de fato no ambiente escolar. Devemse proporcionar textos que venham corresponder com a realidade e necessidade dos alunos, tornando-o uma leitura prazerosa.

Assim como a leitura, a escrita também tem seu status social, como afirma Stubbs (2002) ao dizer que ela tem o papel de transmitir informações, seja por meio da comunicabilidade por ela permitida, seja pela pessoalidade de pensamento cognitivo.

Com isso, o autor definiu as funcionalidades que a língua escrita tem a favor do sujeito, visto que, a língua escrita também é um processo de comunicação. E havendo um domínio desse processo 0 aluno tornar-se-á um ser capaz de produzir seu próprio conhecimento.

Marcuschi (2001), afirma que a escrita trata-se de um processo de produção textual-discursiva fundamental no que se refere ao fator da comunicação em sociedade.

Assim como a leitura e a escrita, a oralidade também é um fator social que estar presente em nosso cotidiano de forma articulada. Uma contribui para o desenvolvimento da outra.

Marcuschi (2001) afirma que a oralidade é uma forma comunicativa que faz uso do som emitido pela fala. Sendo assim, pode-se considerar como prática de interação social e que de acordo com o nível de informação do falante pode ser usada de maneira formal ou informal.

E a escola em inúmeras vezes insiste em julgar o informal em seu contexto escolar e priorizar o mais formal, sendo que em muitos casos o docente se ver incapaz de "corrigir" o aluno por não possuir o domínio da língua-padrão. Como afirma Bortoni-Ricardo (2005) ao mencionar que quando o aluno faz uso do dialeto não padrão a tarefa do professor de imediato é interferir, corrigindo-o como se existissem somente uma única forma de expressão (norma padrão da língua), sendo a qual deve ser usada pelo educando. E que a forma como o educando se expressa é considerada errônea pela língua culta padrão. Por isso, precisa ser deixada de lado.

No entanto, dispondo de uma variedade linguística, a escola precisa apresentar ao discente antes de tudo as variações linguísticas que dispomos sem pré-destinar o que é certo e o que é dito errado, uma vez que segundo Bortoni-Ricardo (2005) os educandos precisam ser livres para se expressarem em sala de aula, seja usando a norma culta padrão ou não. O papel do professor é respeitar seu modo de se comunicar, tornando-se assim um aluno participativo e ativo do processo comunicativo no espaço escolar. Além do mais, o educador precisa com base no discurso do educando explicar a variedade do uso da língua pela sociedade e que dependendo do ambiente no qual esteja, deve-se usar a língua adequada aquele ambiente.

A proposta da autora é validade e enriquecedora, pois permiti com que o aluno obtenha um desenvolvimento comunicativo livre em sala de aula, onde o mesmo terá que compreender a diferenciação entre as variantes padrão e não-padrão, conscientizando-se dessa diversidade linguística e das contribuições que cada uma tem em seu determinado espaço social.

Rodrigues (2007) ressalta que, quando a escola valoriza o uso do dialeto padrão, acaba reforçando a desigualdade social, ao passo que a ênfase na língua culta ratifica a língua das camadas sociais mais privilegiadas da sociedade, e favorece também um melhor aprendizado por parte desta que tem sua língua 
mais próxima da qual a escola está se propondo a ensinar, enquanto que o dialeto não padrão do uso da língua falada usado pela população de menos prestígio social são relegadas pela escola, por dar a ênfase na variedade padrão, favorecendo assim uma desigualdade de classe em termos econômicos, políticos, sociais e, sobretudo educacionais.

Com base nessas afirmações, podemos então considerar que muitas escolas deixam de desenvolver uma prática comunicativa que seja eficaz para os discentes, impossibilitando o ato de fala principalmente para os menos favorecidos na classe social.

A escola precisa estar ciente que naturalmente, os falantes de uma língua primeiro adquirem e passam a usar as variedades informais, as étnico - materno - familiares e/ou as populares e, só bem depois, lenta e gradualmente, aprendem os estilos e gêneros formais que os aproximam da linguagem padrão/culta.

Afinal, o ser humano é perfeitamente capaz de conviver com e de usar mais de uma variedade linguística, escolhendo a mais adequada ao lugar, momento e contexto em que se anuncia

\section{CONSIDERAÇÕES FINAIS}

Embasadas nestas reflexões consideramos relevante que as práticas de letramento, escrita, leitura e oralidade se deem no contexto do espaço escolar de forma articulada, pois fazem parte de uma mesma língua. A aquisição desses saberes linguísticos tornam-se necessários no processo comunicativo, possibilitando tanto aos alunos como o professor de se posicionarem de forma crítica e que não haja imposição de um sobre o outro quanto ao processo de correção de escrita, leitura oralidade e fala, sobretudo. Mas de forma a esclarecer as diversas formas de uso dessas modalidades da língua.

Sendo assim, um sujeito atuante, sente-se motivado a participar desse processo educacional, sabendo que, é por meio do processo linguístico que se transmiti uma mensagem ao interlocutor.

Portanto, devemos trabalhar o letramento, a escrita, a leitura e a oralidade, de forma que possamos proporcionar ao educando uma aprendizagem de qualidade social, em que ele aprenda a fazer uso da língua de acordo com o contexto em que estiver inserido, mas para isso a escola precisa esclarecer a ele a diversidade do uso da língua falada e suas formas de apropriação pela população.

\section{REFERÊNCIAS}

1. STUBBS, Michael. A língua na educação. In: BAGNO, Marcos; STUBBS, Michael; GAGNÉ; Gilles. Língua materna: letramento, variação e ensino. - São Paulo: Parábola, 2002.

2. BORTONI-RICARDO, Stella Maria. Nós cheguemu na escola, e agora? : sociolinguística \& educação. - São Paulo: Parábola Editorial, 2005.

3. BOURDIEU, Pierre; PASSERON, Jean-Claude; tradução de Reynaldo Bairão; revisão de Pedro Benjamin Garcia e Ana Maria Baeta. A reprodução: elementos para uma teoria do sistema de ensino. 3. ed. - Petrópolis, RJ: Vozes, 2010.

4. RODRIGUES, Doriedson do S. Escola, linguagem e camadas populares: uma questão de identidade e cidadania. Educação do Campo na Amazônia: uma experiência/Organizadores: Gilmar Pereira da Silva et al. Belém: EDUFPA, 2007.

5. MARCUSCHI, Luiz Antônio. Da fala para a escrita: atividades de retextualização. - São Paulo: Cortez, 2001.

6. SOUSA, Aurilene Amaral. As atividades de leitura cultivadas na comunidade Cuxipiari Furo Grande. (Org.) Gilmar Pereira da Silva e Doriedson S. Rodrigues. Linguagem e educação na Amazônia: Faces e Interfaces de Pesquisas. V III: Práticas de leitura e escrita. UFPA, 2010. 